\title{
Direet Displacement-Based Design: Use of Inelastic vs. Elastic Design Spectra
}

\author{
Anil K. Chopra, M.EERI, and Rakesh K. Goel, M.EERI
}

\begin{abstract}
Direct displacement-based design requires a simplified procedure to estimate the seismic deformation of an inelastic SDF system, representing the first (elastic) mode of vibration of the structure. This step is usually accomplished by analysis of an "equivalent" linear system using elastic design spectra. In this paper, an equally simple procedure is developed that is based on the well-known concepts of inelastic design spectra. We demonstrate that the procedure provides the following: (1) accurate values of displacement and ductility demands, and (2) a structural design that satisfies the design criteria for allowable plastic rotation. In contrast, the existing procedure using elastic design spectra for equivalent linear systems in shown to underestimate significantly the displacement and ductility demands. The existing procedure is shown to be deficient in yet another sense; the acceptable value of the plastic rotation, leaving an erroneous impression that the allowable plastic rotation constraint has been satisfied.
\end{abstract}

\section{INTRODUCTION}

Direct displacement-based design is being advocated as a more rational and relevant approach to seismic design of structures, compared to traditional strength-based design (Shibata and Sozen 1976; Moehle 1992; Kowalsky, Priestley, and MacRae 1994). Displacement-based design involves several steps (to be described later), one of which is to estimate the seismic deformation of an inelastic SDF system representing the first (elastic) mode of vibration of the MDF system. In some of the present procedures, this step is accomplished by approximate methods in which the nonlinear system is replaced by an "equivalent" linear system (Shibata and Sozen 1976; Priestley, Seible, and Calvi 1996; Priestley and Calvi 1997). The period and damping of this linear system are determined by the secant stiffness method (Jennings 1968, Iwan and Gates 1979) or its variants, e.g., the substitute structure method (Shibata and Sozen 1976). While a possible approach, this equivalent linear system is not essential to displacement-based design. However, one may be left with a different impression on reading: "the key element of the procedure is that stiffness and damping of the structure are characterized by secant properties at maximum response, rather than based on initial elastic properties" (Priestley and Calvi 1997).

(AKC) Johnson Professor, Department of Civil \& Environmental Engineering, University of California, Berkeley, CA 94720-1710

(RKG) Associate Professor, Department of Civil \& Environmental Engineering, California Polytechnic State University, San Luis Obispo, CA 93407 
The purpose of this paper is to demonstrate application of inelastic design spectra to direct displacement-based design of structures. The resulting design procedure is shown to produce a structural design that satisfies the design criteria. In contrast, it is shown that the design produced by the procedure that uses elastic design spectra and equivalent linear systems does not necessarily satisfy the design criteria. In particular, it can leave an erroneous impression that the allowable plastic rotation constraint has been satisfied.

To focus on this theme, this presentation is intentionally restricted to structures idealized as SDF systems with bilinear force-deformation relations (Figure 1). The distraction of approximations inherent in a one-mode representation of MDF systems and bilinear idealization of a pushover curve are thus avoided.

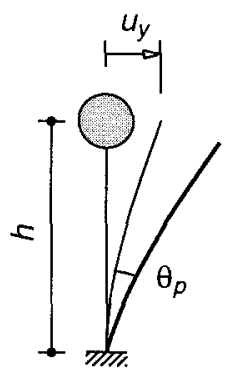

(a)

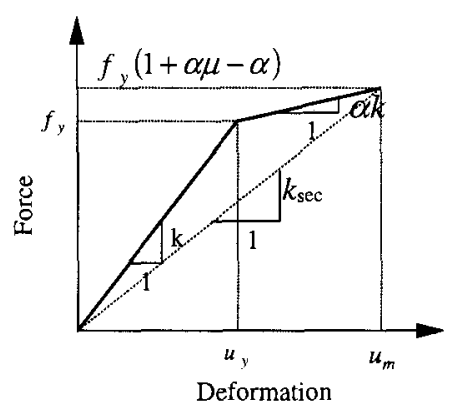

(b)

Figure 1. Idealized SDF system with bilinear force-deformation relation.

\section{DISPLACEMENT-BASED DESIGN USING ELASTIC DESIGN SPECTRA}

\section{EQUIVALENT LINEAR SYSTEM}

Needed in existing displacement-based design procedures, the properties of the equivalent linear system are summarized here. Consider an inelastic SDF system with bilinear force-deformation relationship on initial loading (Figure 1b). The stiffness of the elastic branch is $k$ and that of the yielding branch is $\alpha k$. The yield strength and yield displacement are denoted by $f_{y}$ and $u_{y}$, respectively. If the peak (maximum absolute) deformation of the inelastic system is $u_{m}$, the ductility factor $\mu=u_{m} / u_{y}$.

For the bilinear system of Figure $1 b$, the natural vibration period of the equivalent linear system with stiffness equal to $k_{\text {sec }}$, the secant stiffness, is

$$
T_{e q}=T_{n} \sqrt{\frac{\mu}{1+\alpha \mu-\alpha}}
$$

where $T_{n}$ is the natural vibration period of the system vibrating within its linearly elastic range $\left(u \leq u_{y}\right)$.

The most common method for defining equivalent viscous damping is to equate the energy dissipated in a vibration cycle of the inelastic system and of the equivalent linear 
system. Based on this concept, it can be shown that the equivalent viscous damping ratio is (Chopra and Goel 1999):

$$
\zeta_{e q}=\frac{2}{\pi} \frac{(\mu-1)(1-\alpha)}{\mu(1+\alpha \mu-\alpha)}
$$

The total viscous damping of the equivalent linear system is

$$
\hat{\zeta}_{e q}=\zeta+\zeta_{e q}
$$

where $\zeta$ is the viscous damping ratio of the bilinear system vibrating within its linearly elastic range $\left(u \leq u_{y}\right)$.

Equations 1 and 2 are plotted in Figure 2 where the variation of $T_{e q} / T_{n}$ and $\zeta_{e q}$ with $\mu$ is shown for four values of $\alpha$. For yielding systems $(\mu>1), T_{e q}$ is longer than $T_{n}$ and $\zeta_{e q}>0$.

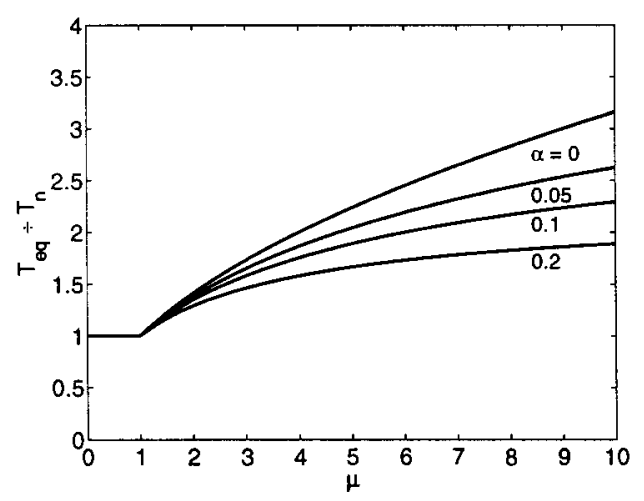

(a)

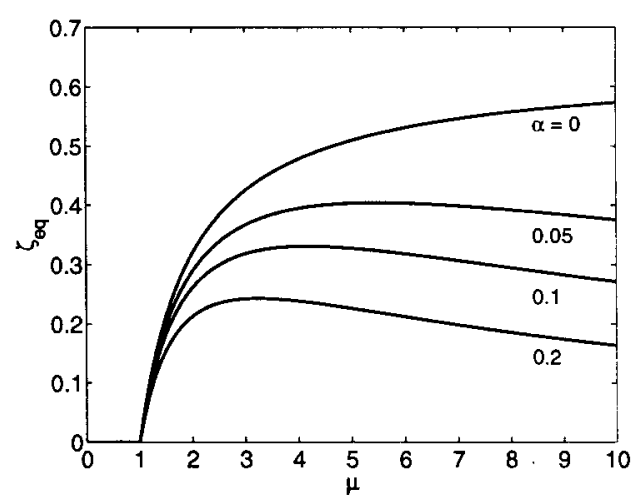

(b)

Figure 2. Variation of period and viscous damping of the equivalent linear system with ductility.

\section{ELASTIC DESIGN SPECTRA}

To implement the existing displacement-based design procedure, an elastic design spectrum is needed. We have chosen to construct this spectrum by the procedures of Newmark and Hall (1982). This procedure is illustrated in Figure 3, where $\ddot{u}_{g o}, \dot{u}_{g o}$, and $u_{g o}$ are the peak values of the ground acceleration, velocity, and displacement, respectively, and $\alpha_{A}, \alpha_{v}$, and $\alpha_{D}$ are the amplification factors that depend on the damping ratio and the probability of exceedance. For median-plus-one-standard-deviation spectrum with $15.9 \%$ probability of exceedance, these factors for the acceleration-, velocity-, and displacementsensitive regions of the spectrum are:

$$
\alpha_{A}=4.38-1.04 \ln \zeta, \alpha_{V}=3.38-0.67 \ln \zeta \text {, and } \alpha_{D}=2.73-0.45 \ln \zeta
$$

in which $\zeta$ is the damping ratio in percent. Observe that the period values associated with points $a, b, e$, and $f$ on the spectrum are fixed; the values shown in Figure 3 are for firm ground. Points $c$ and $d$ are located at the intersection of the constant- $A$, constant $V$, and constant $D$ branches of the spectrum. The locations of these intersection points vary with 
damping ratio because they depend on the amplification factors $\alpha_{A}, \alpha_{v}$, and $\alpha_{D}$. Further details of this procedure are available in Chopra (1995: Chapter 6).

The design spectrum can also be plotted as a pseudo-acceleration design spectrum. Figure 4 presents such a spectrum, which is a 5\% damped, median-plus-one-standard-deviation spectrum constructed for $\ddot{u}_{g o}=1 g, \dot{u}_{g o}=122 \mathrm{~cm} / \mathrm{s}(48 \mathrm{in} / \mathrm{s})$, and $u_{g o}=91.4 \mathrm{~cm}$ (36 in). The acceleration-sensitive, velocity-sensitive, and displacement-sensitive regions of the spectrum have been identified for later reference.

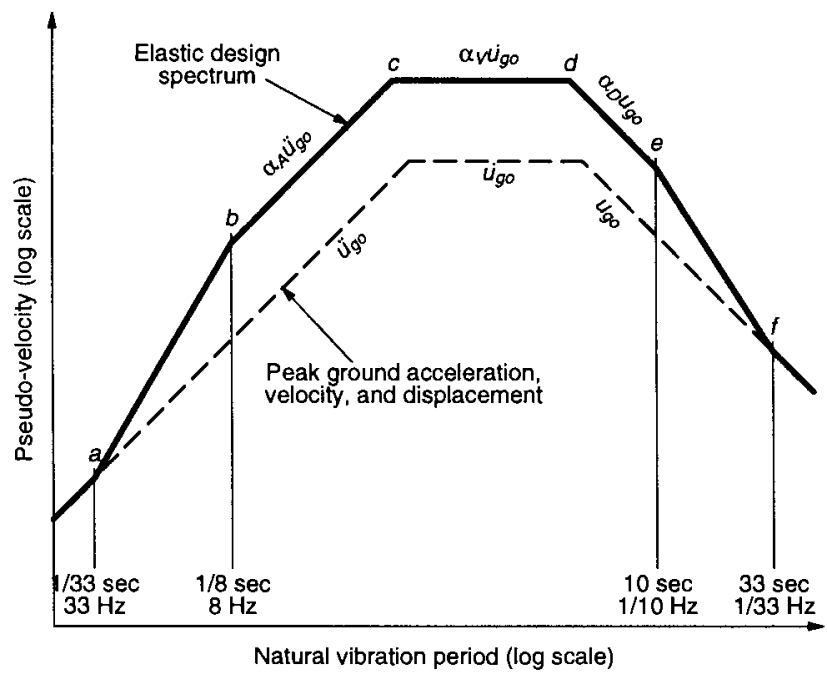

Figure 3. Construction of elastic design spectrum by Newmark-Hall procedure.

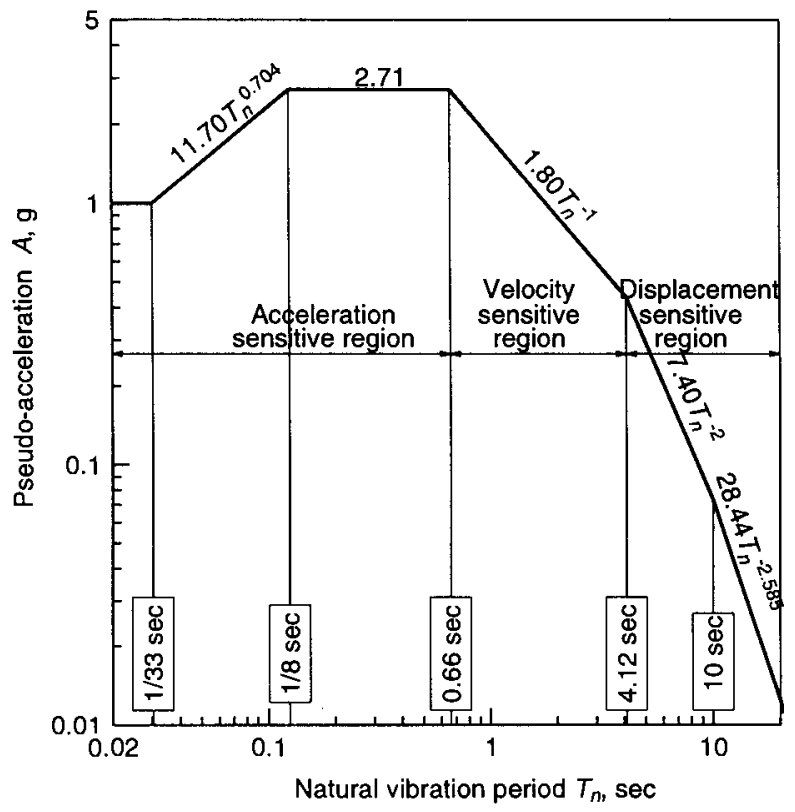

Figure 4. Elastic pseudo-acceleration design spectrum. 
Needed in displacement-based design is the displacement (or deformation) design spectrum which can be determined from Figure 4, using the well-known relationship between pseudo-acceleration $A$ and deformation $D$ :

$$
u_{m}=D=\left(\frac{T_{n}}{2 \pi}\right)^{2} A
$$

Figure 5 shows such spectra for several values of the damping ratio.

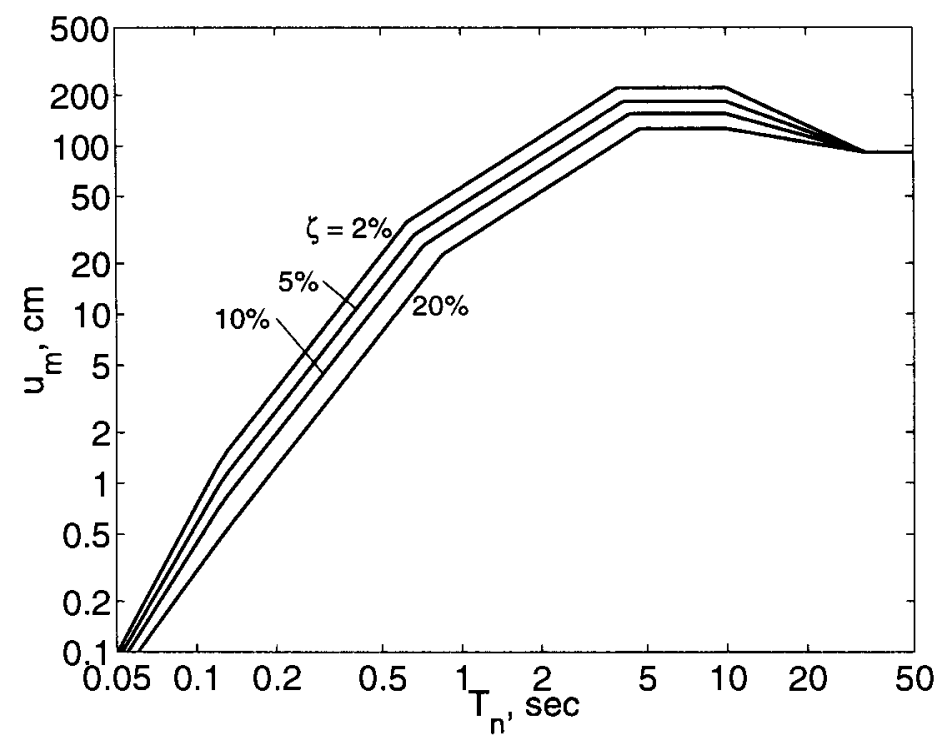

Figure 5. Elastic deformation design spectrum.

\section{STEP-BY-STEP PROCEDURE}

Adapted from Priestley and Calvi (1997), a direct displacement-based design procedure for bilinear SDF systems (Figures 1a and 1b) using elastic design spectra is outlined as a sequence of steps:

1. Estimate the yield deformation $u_{y}$ for the system.

2. Determine acceptable plastic rotation $\theta_{p}$ of the hinge at the base.

3. Determine design displacement $u_{m}$

$$
u_{m}=u_{y}+h \theta_{p}
$$

and design ductility factor $\mu=u_{m} / u_{y}$.

4. Estimate the total equivalent viscous damping, $\hat{\zeta}_{e q}$, for the design ductility factor from Equations 2 and 3 or Figure $2 b$.

5. Enter the deformation design spectrum for elastic systems with known $u_{m}$ and $\hat{\zeta}_{e q}$ to read $T_{e q}$ (Figure 5). Determine the secant stiffness 


$$
k_{\mathrm{sec}}=\frac{4 \pi^{2}}{T_{e q}^{2}} m
$$

where $m$ is the mass of the system.

6. Determine the required yield strength $f_{y}$ from Figure $1 \mathrm{~b}$ :

$$
f_{y}=\frac{k_{\text {sec }} u_{m}}{1+\alpha \mu-\alpha}
$$

7. Estimate member sizes and detailing (reinforcement in $\mathrm{R} / \mathrm{C}$ structures, connections in steel structures) to provide $f_{y}$. Calculate initial elastic stiffness $k$ and $u_{y}=f_{y} / k$.

8. Repeat steps 3 to 7 until a satisfactory solution is obtained.

\section{EXAMPLES}

The displacement-based design procedure using elastic design spectra and equivalent linear systems will be implemented for two example systems. The elastic vibration period of the first example system falls in the velocity-sensitive region of the design spectrum, and of the second system in the acceleration-sensitive region.

\section{Example 1}

Consider a portion of a long reinforced-concrete viaduct that is a part of a freeway. The total weight of the superstructure, $190 \mathrm{kN} / \mathrm{m}$, is supported on identical bents $9 \mathrm{~m}$ high, uniformly spaced at $39.6 \mathrm{~m}$. Each bent consists of a single circular column $1.5 \mathrm{~m}$ in diameter (Figure 6a). Using the design procedure described earlier, we will design the longitudinal reinforcement of the column for the design earthquake defined by Figure 4 scaled to $\ddot{u}_{g o}=0.5 \mathrm{~g}$.

For the transverse ground motion, the viaduct can be idealized as an SDF system (Figure 6b) with its lateral stiffness computed from

$$
k=\frac{3 E I}{h^{3}}
$$

where $E$ is the elastic modulus of concrete, $I$ is the effective moment of inertia of the reinforced-concrete cross section, and $h$ is the column height. Based on the American Concrete Institute design provisions ACI 318-95, the effective EI for circular columns subjected to lateral load (MacGregor 1997) is given by

$$
E I=E_{c} I_{g}\left(0.2+2 \rho_{t} \gamma^{2} \frac{E_{s}}{E_{c}}\right)
$$

where $I_{g}$ is the second moment of inertia of the gross section, $E_{c}$ and $E_{s}$ are the elastic moduli of concrete and reinforcing steel, $\rho_{t}$ is the longitudinal reinforcement ratio, and $\gamma$ is the ratio of the distances from the center of the column to the center of the outermost reinforcing bars and to the column edge.

The system properties selected are: concrete strength $=27.6 \mathrm{MPa}(4 \mathrm{ksi})$, steel strength $=$ $413 \mathrm{MPa}(60 \mathrm{ksi})$ and $\gamma=0.9$. The mass of the idealized SDF system is the tributary mass for one bent, i.e., the mass of $39.6 \mathrm{~m}$ length of the superstructure, $m=w / g=$ 
$(7517 \times 1000 \mathrm{~N}) / 9.8 \mathrm{~m} / \mathrm{s}^{2}=767041 \mathrm{~kg}$. The initial elastic vibration period of this system is $1.82 \mathrm{~s}$, which falls in the velocity-sensitive region of the design spectrum.

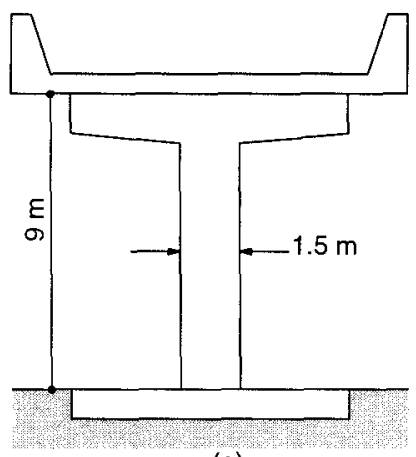

(a)

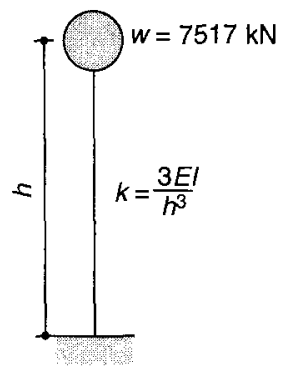

(b)

Figure 6. Example single-column bent and idealized SDF system.

The step-by-step procedure described earlier in this section is now implemented as follows:

1. An initial estimate of $u_{y}=4.5 \mathrm{~cm}$.

2. The plastic rotation acceptable at the base of the column is $\theta_{p}=0.02$ radians.

3. The design displacement given by Equation 6 is $u_{m}=u_{y}+h \theta_{p}=4.5+900 \times 0.02=22.5$ $\mathrm{cm}$ and the design ductility factor is $\mu=u_{m} / u_{y}=22.5 / 4.5=5$.

4. For $\alpha=5 \%$ and $\mu=5$, Equations 2 and 3 give $\hat{\zeta}_{\text {eq }}=45 \%$.

5. The deformation design spectrum for elastic systems is shown in Figure 7 for $\hat{\zeta}_{e q}=45 \%$. Corresponding to $u_{m}=22.5 \mathrm{~cm}$ this spectrum gives $T_{e q}=2.81 \mathrm{~s}$ and $k_{\text {sec }}$ is computed by Equation $7, k_{\mathrm{sec}}=(2 \pi / 2.81)^{2} \times 767041=3.835 \times 10^{6} \mathrm{~N} / \mathrm{m}=38.35 \mathrm{kN} / \mathrm{cm}$.

6. The yield strength is given by Equation $8, f_{y}=(38.35 \times 22.5) /(1+0.05 \times 5-0.05)=$ $719.1 \mathrm{kN}$.

7. The circular column is then designed using ACI318-95 for axial load due to superstructure weight of $7517 \mathrm{kN}$ plus column self weight of $375 \mathrm{kN}$ and the bending moment due to lateral force $=f_{y}: M=h f_{y}=6472 \mathrm{kN}-\mathrm{m}$. For the resulting column design, $\rho_{t}=1.19 \%$, flexural strength $=7395 \mathrm{kN}-\mathrm{m}$, and lateral strength $=821.7 \mathrm{kN}$. For $\rho_{t}=1.19 \%$, Equation 10 gives $E I=2.22 \times 10^{6} \mathrm{kN}-\mathrm{m}^{2}$; using this $E I$ value Equation 9 gives $k=91.3 \mathrm{kN} / \mathrm{cm}$. The yield deformation is $u_{y}=f_{y} / k=821.7 / 91.3=9 \mathrm{~cm}$.

8. Since the yield deformation computed in Step 7 differs significantly from the initial estimate of $u_{y}=4.5 \mathrm{~cm}$, iterations are necessary. The results of such iterations are summarized in Table 1.

The procedure converged after three iterations giving a column design with $\rho_{t}=1.3 \%$. This column has an initial stiffness, $k=95.17 \mathrm{kN} / \mathrm{cm}$ and lateral yield strength, $f_{y}=839.7 \mathrm{kN}$. 
Table 1. Results of iterative displacement-based design procedure using elastic design spectrum for Example 1

\begin{tabular}{|c|c|c|c|c|c|c|c|c|c|c|c|}
\hline No. & $u_{y}$ & $u_{m}$ & $\mu$ & $\hat{\zeta}_{e q}$ & $T_{e q}$ & $k_{\text {sec }}$ & $f_{y}$ & $\rho_{t}$ & $\begin{array}{c}\text { Design } \\
f_{y} \\
(\mathrm{kN})\end{array}$ & $\begin{array}{c}k \\
(\mathrm{kN} / \mathrm{cm})\end{array}$ & $\begin{array}{c}u_{y} \\
(\mathrm{~cm})\end{array}$ \\
\hline 1 & 4.50 & 22.5 & 5.00 & 45 & 2.81 & 38.35 & 719.1 & 1.19 & 821.7 & 91.34 & 9.00 \\
\hline 2 & 9.00 & 27.0 & 3.00 & 42 & 3.16 & 30.41 & 746.4 & 1.30 & 839.7 & 95.17 & 8.82 \\
\hline 3 & 8.82 & 26.8 & 3.04 & 42 & 3.14 & 30.62 & 745.2 & 1.30 & 839.7 & 95.17 & 8.82 \\
\hline
\end{tabular}

\section{Example 2}

The system of this example is identical to Example 1 (Figure 6) except that the bents are $4 \mathrm{~m}$ high. The initial elastic vibration period of this system is $0.56 \mathrm{~s}$, which falls in the acceleration-sensitive region of the design spectrum. For this system, the procedure converged after just two iterations, giving a column design with $\rho_{t}=1 \%$. This column has an initial stiffness, $k=967.2 \mathrm{kN} / \mathrm{cm}$ and lateral yield strength, $f_{y}-1715 \mathrm{kN}$. The results for this system are summarized in Table 2 .

Table 2. Results of iterative displacement-based design procedure using elastic design spectrum for Example 2

\begin{tabular}{|c|c|c|c|c|c|c|c|c|c|c|c|}
\hline No. & $u_{y}$ & $u_{m}$ & $\mu$ & $\xi_{e q}$ & $T_{e q}$ & $k_{\text {sec }}$ & $f_{y}$ & $\rho_{i}$ & $\begin{array}{c}\text { Design } \\
f_{y} \\
(\mathrm{kN})\end{array}$ & $k$ & $u_{y}$ \\
& $(\mathrm{kN} / \mathrm{cm})$ & $(\mathrm{cm})$ & & $(\%)$ & $(\mathrm{s})$ & $(\mathrm{kN} / \mathrm{cm})$ & $(\mathrm{kN})$ & $(\%)$ & $(\mathrm{cm})$ \\
\hline 1 & 2.00 & 10.0 & 5.00 & 45 & 1.40 & 155.5 & 1296 & 1.00 & 1715 & 967.2 & 1.77 \\
\hline 2 & 1.77 & 9.77 & 5.51 & 45 & 1.38 & 158.5 & 1264 & 1.00 & 1715 & 967.2 & 1.77 \\
\hline
\end{tabular}

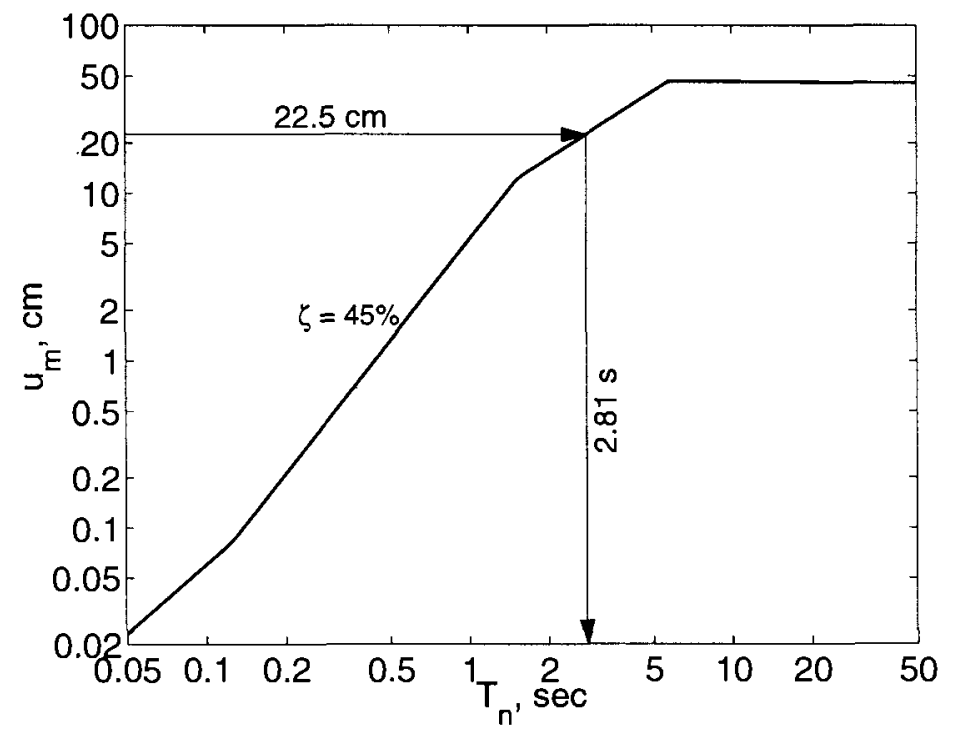

Figure 7. Calculation of $T_{e q}$ for first iteration of the displacement-based design procedure using elastic design spectra for Example 1. 


\section{DISPLACEMENT-BASED DESIGN USING INELASTIC DESIGN SPECTRA}

Presented next is a direct displacement-based design procedure that uses the well-known constant-ductility design spectra instead of the elastic design spectra for equivalent linear systems.

\section{INELASTIC DESIGN SPECTRUM}

A constant-ductility spectrum for an elastoplastic hysteretic system is a plot of $A_{y}$ versus the initial elastic period $T_{n}$ for selected values of $\mu$. The pseudo-acceleration $A_{y}$ is related to the yield strength $f_{y}$ by

$$
f_{y}=\frac{A_{y}}{g} w
$$

where $w$ is the weight of the system: The yield strength reduction factor is given by

$$
R_{y}=\frac{f_{o}}{f_{y}}=\frac{A}{A_{y}}
$$

where

$$
f_{o}=\left(\frac{A}{g}\right) w
$$

is the minimum yield strength required for the structure to remain elastic during the earthquake; $A$ is the pseudo-acceleration ordinate of the elastic design spectrum at $\left(T_{n}, \zeta\right)$.

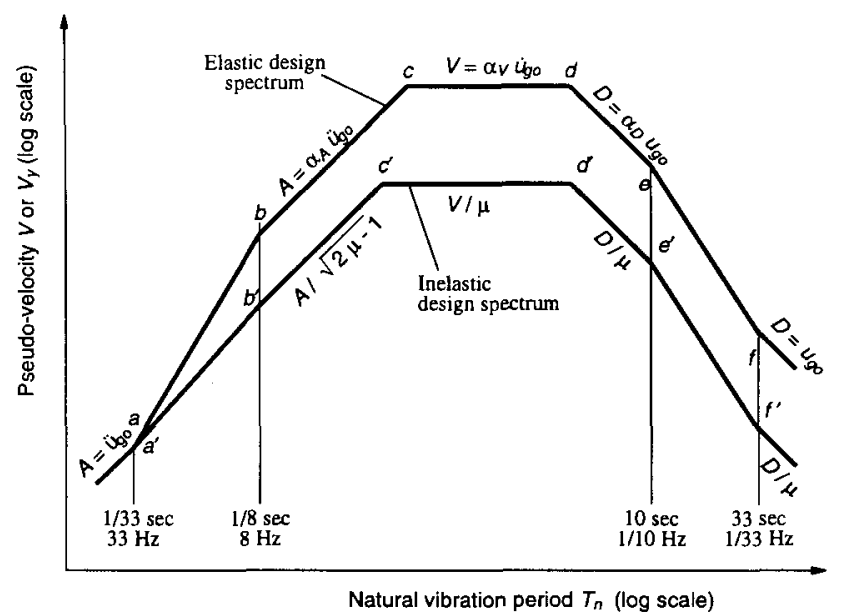

Figure 8. Construction of inelastic design spectrum by Newmark-Hall procedure.

A constant-ductility design spectrum is established by dividing the elastic design spectrum by appropriate ductility-dependent factors that depend on $T_{n}$ (Figure 8). The earliest recommendation for the reduction factor, $R_{y}$, goes back to the work of Veletsos and Newmark (1960), which is the basis for the inelastic design spectra developed by Newmark and Hall (1982): 


$$
R_{y}= \begin{cases}1 & T_{n}<T_{a} \\ (2 \mu-1)^{\beta / 2} & T_{a}<T_{n}<T_{b} \\ \sqrt{2 \mu-1} & T_{b}<T_{n}<T_{c^{\prime}} \\ \frac{T_{n}}{T_{c}} \mu & T_{c^{\prime}}<T_{n}<T_{c} \\ \mu & T_{n}>T_{c}\end{cases}
$$

This equation is plotted in Figure 9 for $\mu=4$.

Starting with the elastic design spectrum of Figure 4 and these $R_{y}-\mu$ relations for acceleration-, velocity-, and displacement-sensitive spectral regions, the inelastic design spectrum constructed by the procedure described in Chopra (1995, Chapter 7) is shown in Figure 8 and the corresponding pseudo-acceleration design spectrum in Figure 10a.

In recent years, several recommendations for the reduction factor have been developed (Krawinkler and Nassar 1992; Vidic, Fajfar, and Fischinger 1994; Riddell, Hidalgo, and Cruz 1989; Tso and Naumoski 1991; Miranda and Bertero 1994). Equations for the first two of these recommendations are available in Chopra and Goel (1999) and plotted in Figure 9. The corresponding inelastic design spectra are shown in Figures $10 \mathrm{~b}$ and $10 \mathrm{c}$. The three sets of inelastic spectra in Figure 10 are similar in the velocity-sensitive region of the spectrum, but differ in the acceleration-sensitive region.

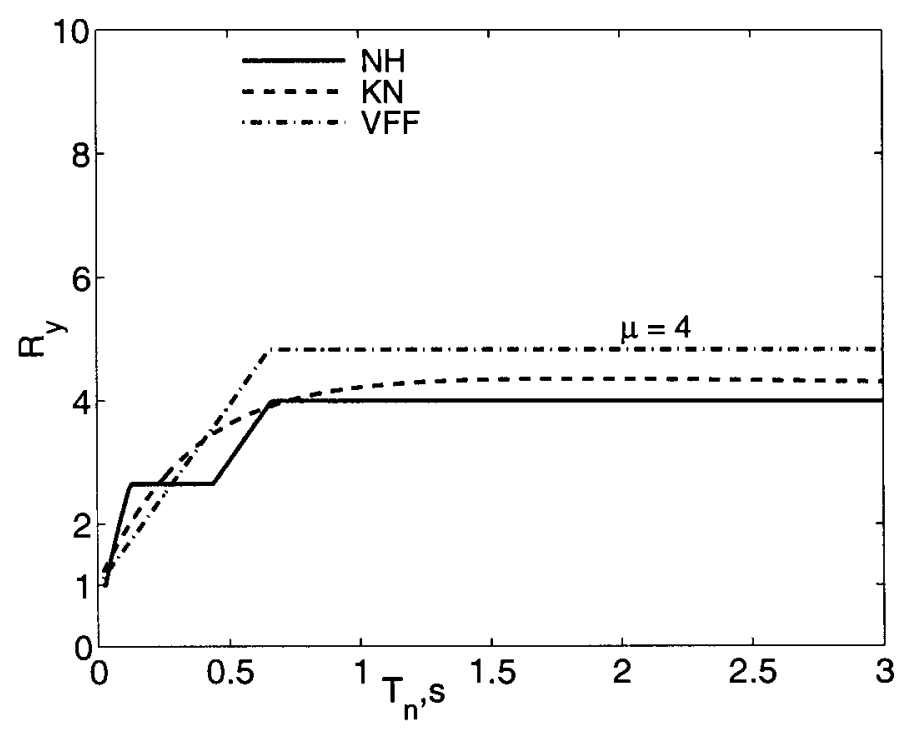

Figure 9. Variation of $R_{y}$ with $T_{n}$ for $\mu=4$ based on three different sources: Newmark and Hall $(\mathrm{NH})$, Krawinkler and Nassar (KN), and Vidic, Fajfar, and Fischinger (VFF).

The peak deformation $u_{m}$ of the inelastic system is given by:

$$
u_{m}=\mu\left(\frac{T_{n}}{2 \pi}\right)^{2} A_{y}=\mu \frac{1}{R_{y}}\left(\frac{T_{n}}{2 \pi}\right)^{2} A
$$


Computed by using Equation 15 and the pseudo-acceleration design spectrum of Figure 10a (or $R_{y}-\mu$ relations of Equation 14), the deformation design spectrum is shown in Figure 11.

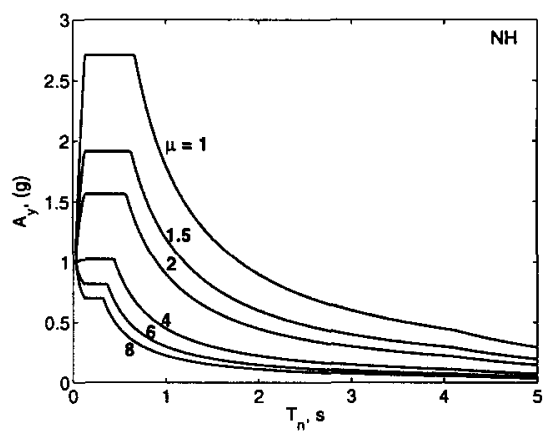

(a)

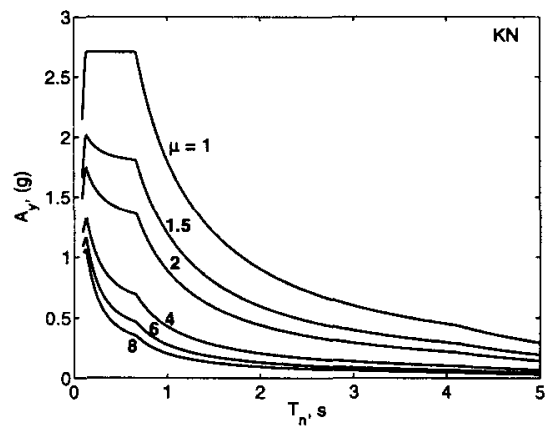

(b)

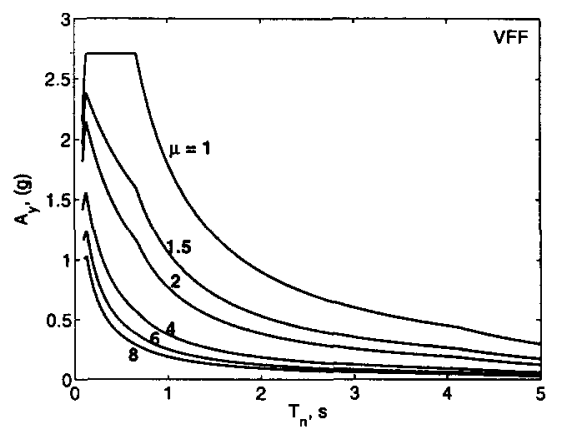

(c)

Figure 10. Inelastic design spectra: (a) Newmark and Hall (1982), (b) Krawinkler and Nassar (1992), and (c) Vidic, Fajfar and Fischinger (1994).

\section{STEP-BY-STEP PROCEDURE}

The first three steps of this procedure are identical to those in the previously-described displacement-based design procedure, and steps 4 to 8 are replaced by the following steps based on the deformation design spectra for inelastic systems (Figure 11).

4. Enter Figure 11 with known $u_{m}$ and $\mu$ to read $T_{n}$. Determine the initial elastic stiffness: 


$$
k=\frac{4 \pi^{2}}{T_{n}^{2}} m
$$

5. Determine the required yield strength

$$
f_{y}=k_{u_{y}}
$$

6. Estimate member sizes and detailing (reinforcement in $\mathrm{R} / \mathrm{C}$ structures, connections in steel structures, etc.) to provide the strength determined from Equation 17. For the resulting design of the structure, calculate the initial elastic stiffness $k$ and yield deformation $u_{y}=f_{y} / k$.

7. Repeat steps 3 to 6 until a satisfactory solution is obtained.

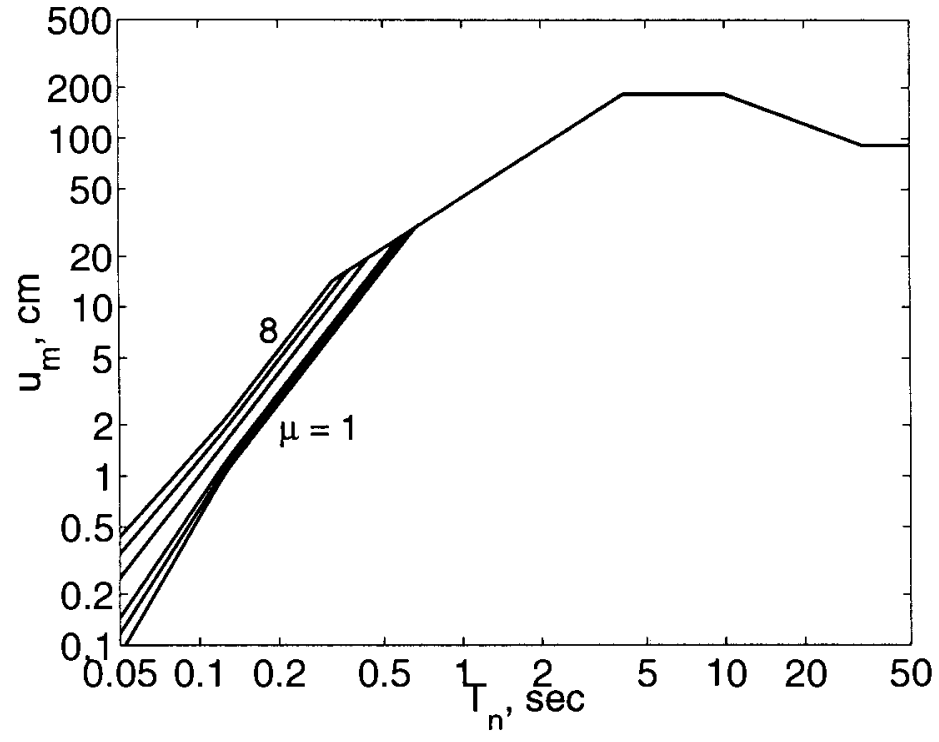

Figure 11. Inelastic deformation design spectra.

The graphical implementation of Step 4 in the modified design procedure may be attractive for its similarity to the previous procedure. However, the graphical feature is not essential and the Step 4 can be implemented numerically; from Equation 15

$$
T_{n}=2 \pi \sqrt{\frac{u_{m}}{A} \frac{R_{y}}{\mu}}
$$

where $R_{y}$ and $\mu$ are related by Equation 14, for example. Because this relation depends on $T_{n}$, iteration may be necessary to determine $T_{n}$ from Equation 18.

\section{EXAMPLES}

The step-by-step procedure described in this section is now implemented for the two systems designed previously by the displacement-based design procedure using the elastic design spectra. 


\section{Example 1}

1. An initial estimate of $u_{y}=4.5 \mathrm{~cm}$.

2. The plastic rotation acceptable at the base of the column is $\theta_{p}=0.02$ radians.

3. The design displacement given by Equation 6 is $u_{m}=u_{y}+h \theta_{p}=4.5+900 \times 0.02=22.5$ $\mathrm{cm}$ and the design ductility factor is $\mu=u_{m} / u_{y}=22.5 / 4.5=5$.

4. The deformation design spectrum for inelastic systems is shown in Figure 12 for $\mu=5$. Corresponding to $u_{m}=22.5 \mathrm{~cm}$, this spectrum gives $T_{n}=1.01 \mathrm{~s}$ and $k$ is computed by Equation $16, k=(2 \pi / 1.01)^{2} \times 767041=29.9 \times 10^{6} \mathrm{~N} / \mathrm{m}=298.7 \mathrm{kN} / \mathrm{cm}$.

5. The yield strength is given by Equation $17, f_{y}=k u_{y}=298.7 \times 4.5=1344 \mathrm{kN}$.

6. The circular column is then designed using ACI318-95 for axial load due to superstructure weight of $7517 \mathrm{kN}$ plus column self weight of $375 \mathrm{kN}$ and the bending moment due to lateral force $=f_{y}: M=h f_{y}=12096 \mathrm{kN}-\mathrm{m}$. For the resulting column design, $\rho_{t}=3.62 \%$, flexural strength $=12976 \mathrm{kN}-\mathrm{m}$, and lateral strength $=1441 \mathrm{kN}$. For $\rho_{l}=3.62 \%$, Equation 10 gives $E I=4.24 \times 10^{6} \mathrm{kN}-\mathrm{m}^{2}$; using this $E I$ value Equation 9 gives $k=174.4 \mathrm{kN} / \mathrm{cm}$. The yield deformation is $u_{y}=f_{y} / k=1441 / 174.4=8.27 \mathrm{~cm}$.

7. Since the yield deformation computed in Step 6 differs significantly from the initial estimate of $u_{y}=4.5 \mathrm{~cm}$, iterations are necessary. The results of such iterations are summarized in Table 3.

The procedure converged after five iterations giving a column design with $\rho_{t}=5.5 \%$. This column has an initial stiffness, $k=238.6 \mathrm{kN} / \mathrm{cm}$ and lateral yield strength, $f_{y}=1907 \mathrm{kN}$.

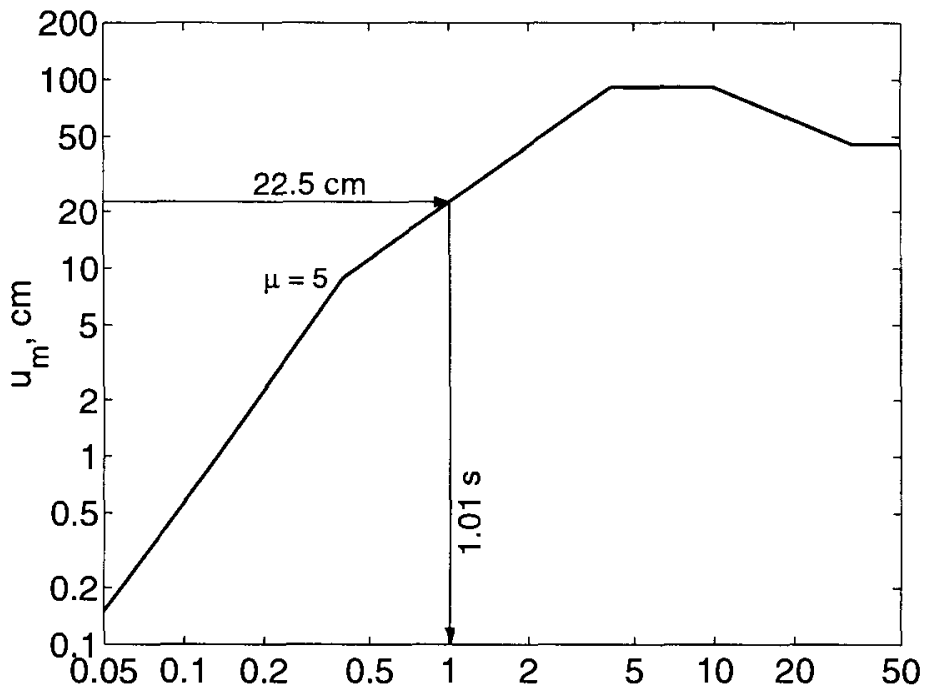

Figure 12. Calculation of $T_{n}$ for first iteration of the displacement-based design using inelastic design spectra for Example 1. 
Table 3. Results of iterative displacement-based design procedure using inelastic design spectra for Example 1

\begin{tabular}{|c|c|c|c|c|c|c|c|c|c|c|}
\hline No. & $\begin{array}{c}u_{y} \\
(\mathrm{~cm})\end{array}$ & $\begin{array}{c}u_{m} \\
(\mathrm{~cm})\end{array}$ & $\mu$ & $\begin{array}{c}T_{n} \\
(\mathrm{~s})\end{array}$ & $\begin{array}{c}k \\
(\mathrm{kN} / \mathrm{cm})\end{array}$ & $\begin{array}{c}f_{y} \\
(\mathrm{kN})\end{array}$ & $\begin{array}{c}\rho_{t} \\
(\%)\end{array}$ & $\begin{array}{c}\text { Design } f_{y} \\
(\mathrm{kN})\end{array}$ & $\begin{array}{c}\text { Design } k \\
(\mathrm{kN} / \mathrm{cm})\end{array}$ & $\begin{array}{c}u_{y} \\
(\mathrm{~cm})\end{array}$ \\
\hline $\mathrm{l}$ & 4.50 & 22.5 & 5.00 & 1.01 & 298.7 & 1344 & 3.62 & 1441 & 174.4 & 8.27 \\
\hline 2 & 8.27 & 26.3 & 3.18 & 1.18 & 219.1 & 1812 & 5.55 & 1912 & 240.3 & 7.96 \\
\hline 3 & 7.96 & 26.0 & 3.26 & 1.16 & 224.4 & 1786 & 5.43 & 1899 & 236.2 & 8.04 \\
\hline 4 & 8.04 & 26.0 & 3.24 & 1.17 & 223.0 & 1793 & 5.50 & 1907 & 238.6 & 7.99 \\
\hline 5 & 7.99 & 26.0 & 3.25 & 1.16 & 223.8 & 1789 & 5.50 & 1907 & 238.6 & 7.99 \\
\hline
\end{tabular}

\section{Example 2}

For this system, the procedure converged after four iterations giving a column design with $\rho_{t}=3.1 \%$. This column has an initial stiffness, $k=1784 \mathrm{kN} / \mathrm{cm}$ and lateral yield strength, $f_{y}=2965 \mathrm{kN}$. The results for this system are summarized in Table 4 .

Table 4. Results of iterative displacement-based design procedure using inelastic design spectra for Example 2

\begin{tabular}{|c|c|c|c|c|c|c|c|c|c|c|}
\hline No. & $\begin{array}{c}u_{y} \\
(\mathrm{~cm})\end{array}$ & $\begin{array}{c}u_{m} \\
(\mathrm{~cm})\end{array}$ & $\mu$ & $\begin{array}{c}T_{n} \\
(\mathrm{~s})\end{array}$ & $\begin{array}{c}k \\
(\mathrm{kN} / \mathrm{cm})\end{array}$ & $\begin{array}{c}f_{y} \\
(\mathrm{kN})\end{array}$ & $\begin{array}{c}\rho_{t} \\
(\%)\end{array}$ & $\begin{array}{c}\text { Design } f_{y} \\
(\mathrm{kN})\end{array}$ & $\begin{array}{c}\text { Design } k \\
(\mathrm{kN} / \mathrm{cm})\end{array}$ & $\begin{array}{c}u_{y} \\
(\mathrm{~cm})\end{array}$ \\
\hline 1 & 2.00 & 10.0 & 5.00 & 0.45 & 1512 & 3024 & 3.60 & 3226 & 1979 & 1.63 \\
\hline 2 & 1.63 & 9.63 & 5.91 & 0.43 & 1630 & 2658 & 3.00 & 2907 & 1745 & 1.67 \\
\hline 3 & 1.67 & 9.67 & 5.80 & 0.43 & 1618 & 2696 & 3.10 & 2965 & 1784 & 1.66 \\
\hline 4 & 1.66 & 9.66 & 5.81 & 0.43 & 1620 & 2692 & 3.10 & 2965 & 1784 & 1.66 \\
\hline
\end{tabular}

\section{EVALUATION OF EXAMPLE DESIGNS}

The column design resulting from both procedures is evaluated in this section. Whether a design is satisfactory will be judged by calculating the deformation demand, plastic rotation demand, and ductility demand imposed by the design earthquake. These demands can be computed for a system with known properties (initial elastic stiffness, $k$, mass, $m$, and yieldstrength $f_{y}$ ) by the following procedure:

1. Calculate the initial elastic period, $T_{n}$, from the known mass, $m$, and the initial elastic stiffness, $k$.

2. Determine the pseudo-acceleration $A$ from the elastic design spectrum; the elastic design force, $f_{o}=(A / g) w$.

3. Calculate the yield-strength reduction factor, $R_{y}=f_{o} / f_{y}$, in which $f_{o}$ is computed in Step 2 and $f_{y}$ is known yield-strength of the designed system.

4. Determine the ductility demand $\mu$ using the $R_{y}-\mu-T_{n}$ relations (Equation 14 and Figure 9).

5. Calculate $u_{m}$ from Equation 15, and $\theta_{p}$ from Equation 6, where $u_{y}=f_{y} / k$ and $f_{y}$ is known yield-strength of the system.

The deformation and plastic rotation are computed by this procedure next for the two example systems and compared with those estimated by the two afore-mentioned design procedures. 


\section{STRUCTURAL DESIGN USING ELASTIC DESIGN SPECTRA}

\section{Example 1}

Recall that the initial elastic vibration period $T_{n}=1.82 \mathrm{~s}$ for this example falls in the velocity-sensitive region of the design spectrum. For the final design, $k=95.17 \mathrm{kN} / \mathrm{cm}$ and $f_{y}=839.7 \mathrm{kN}$ (Table 1), and $T_{n}=1.78 \mathrm{~s}$. From the elastic design spectrum, $A=0.505 \mathrm{~g}$ for $T_{n}=1.78 \mathrm{~s}$ and $\zeta=5 \%$, which gives $f_{o}=7517 \times 0.505=3799 \mathrm{kN}$. Then $R_{y}=3799 / 839.7=$ 4.52. Since $T_{n}=1.78 \mathrm{~s}>T_{c^{\prime}}$ Equation 14 gives $\mu=R_{y}=4.52$. Calculated from Equation 15 , $u_{m}=(4.52 / 4.52) \times(1.78 / 2 \pi)^{2} \times 0.505 \times 980=39.7 \mathrm{~cm}$. The yield displacement $u_{y}=839.7 / 95.17$ $=8.82 \mathrm{~cm}$, and Equation 6 gives the plastic rotation $\theta_{p}=(39.7-8.82) / 900=0.0343$ radians .

In designing the structure by using the elastic design spectra for equivalent linear systems, the deformation of the designed structure was estimated to be $26.8 \mathrm{~cm}$ (Table 1 ). However, when the designed structure is analyzed using Equation 15, the deformation demand is $39.7 \mathrm{~cm}$. Which of the two values is more accurate? Clearly it is the latter value because it comes from inelastic design spectra which are based on nonlinear response history analyses of inelastic systems considering a wide range of system parameters and many ground motions (Krawinkler and Nassar 1992; Vidic, Fajfar, and Fischinger 1994). In contrast, the former value comes from an approximate procedure based on equivalent linear systems, a procedure that is known to be inaccurate (Chopra and Goel 2000). Thus the design procedure has underestimated the deformation demand by $100 \times(26.8-39.7) / 39.7=-32.6 \%$.

The displacement-based design procedure based on elastic design spectra for equivalent linear systems has additional deficiencies. Although the structure was designed for an acceptable value of the plastic rotation $\theta_{p}=0.02$ radians, the plastic rotation demand = 0.0343 radians, $72 \%$ more than the acceptable value. Thus the design procedure leaves an erroneous impression that the allowable plastic rotation constraint has been satisfied. Furthermore, the ductility factor of 3.04 computed in the design procedure (Table 1) is much lower than the ductility demand of 4.52 ; the difference is $-32.6 \%$. Underestimating the ductility demand may lead to unconservatively less-ductile detailing. Clearly the procedure has led to an unsatisfactory design.

\section{Example 2}

Recall that the initial elastic vibration period $T_{n}=0.56 \mathrm{~s}$ for this example falls in the acceleration-sensitive region of the design spectrum. For the final design, $k=967.2 \mathrm{kN} / \mathrm{cm}$ and $f_{y}=1715 \mathrm{kN}$ (Table 2), and $T_{n}=0.56 \mathrm{~s}$. From the elastic design spectrum, $A=1.355 \mathrm{~g}$ for $T_{n}=0.56 \mathrm{~s}$ and $\zeta=5 \%$, which gives $f_{o}=7517 \times 1.355=10185 \mathrm{kN}$. Then $R_{y}=$ $10185 / 1715=5.94 . T_{c}=0.67 \mathrm{~s}$ for the selected design spectrum. Assuming, $T_{c^{\prime}}<T_{n}<T_{c}$, Equation 14 gives $\mu=\left(T_{c} / T_{n}\right) \times R_{y}=(0.67 / 0.56) \times 5.94=7.11$. Knowing $\mu=7.11, T_{c^{\prime}}$ can now be calculated as $T_{c^{\prime}}=(\sqrt{2 \mu-1} / \mu) \times T_{c}=(\sqrt{2 \times 7.11-1} / 7.11) \times 0.67=0.34 \mathrm{~s}$. Therefore our initial assumption of $T_{c^{\prime}}<T_{n}<T_{c}$ is correct and no iteration is required. Calculated from Equation $15, u_{m}=(7.11 / 5.94) \times(0.56 / 2 \pi)^{2} \times 1.355 \times 980=12.6 \mathrm{~cm}$. The yield displacement $u_{y}=1715 / 967.2=1.77 \mathrm{~cm}$, and Equation 6 gives the plastic rotation $\theta_{p}=(12.6-1.77) / 400=$ 0.0271 radians. 
The displacement-based design procedure using elastic design spectra predicted the maximum deformation of $9.77 \mathrm{~cm}$ (Table 2) which differs by $-22.5 \%$ compared to the deformation demand of $12.6 \mathrm{~cm}$ from the inelastic design spectrum. The plastic rotation demand $=0.0271$ radians is $30 \%$ more than the acceptable value of 0.02 radians. Furthermore, the ductility factor of 5.51 computed in the design procedure is much lower than the ductility demand of 7.11 ; the difference is $-22.5 \%$. Just as in Example 1 , the procedure has led to an unsatisfactory design without any warning to the designer.

\section{STRUCTURAL DESIGN USING INELASTIC DESIGN SPECTRA}

\section{Example 1}

For the final design, $k=238.6 \mathrm{kN} / \mathrm{cm}$ and $f_{y}=1907 \mathrm{kN}$ (Table 3), and $T_{n}=1.16 \mathrm{~s}$. From the elastic design spectrum, $A=0.775 \mathrm{~g}$ for $T_{n}=1.16 \mathrm{~s}$ and $\zeta=5 \%$, which gives $f_{o}=7517 \times 0.775=5826 \mathrm{KN}$. Then $R_{y}=5826 / 1907=3.06$. Since $T_{n}=1.16 \mathrm{~s}>T_{c}$. Equation 14 gives $\mu=R_{y}=3.06$. Calculated from Equation 15, $u_{m}=$ $(3.06 / 3.06) \times(1.16 / 2 \pi)^{2} \times 0.775 \times 980=25.9 \mathrm{~cm}$. The yield displacement $u_{y}=1907 / 238.6=8.0$ $\mathrm{cm}$, and Equation 6 gives the plastic rotation $\theta_{p}=(25.9-8.0) / 900=0.0199$ radians.

In designing the structure by the procedure based on inelastic design spectra, the deformation demand for the designed structure was estimated to be $26.0 \mathrm{~cm}$ and its ductility demand as 3.25 (Table 3). When the designed structure is analyzed using Equations 11 to 15 , the deformation demand is $25.9 \mathrm{~cm}$ and the ductility demand is 3.06 . Clearly the design procedure has estimated the demands consistent with those predicted by well-established concepts of inelastic design spectra. Furthermore, the plastic rotation demand of 0.0199 radians is essentially identical to the acceptable value of 0.02 radians that was imposed on the design. Clearly the proposed procedure has produced a satisfactory design.

\section{Example 2}

For the final design, $k=1784 \mathrm{kN} / \mathrm{cm}$ and $f_{y}=2965 \mathrm{kN}$ (Table 4), and $T_{n}=0.43 \mathrm{~s}$. From the elastic design spectrum, $A=1.355 \mathrm{~g}$ for $T_{n}=0.43 \mathrm{~s}$ and $\zeta=5 \%$, which gives $f_{o}=7517 \times 1.355=10185 \mathrm{kN}$. Then $R_{y}=10185 / 2965=3.43 . T_{c}=0.67 \mathrm{~s}$ for the selected design spectrum. Assuming, $T_{c^{\prime}}<T_{n}<T_{c}$, Equation 14 gives $\mu=\left(T_{c} / T_{n}\right) \times R_{y}=(0.67 / 0.43)$ $\times 3.43=5.35$. Knowing $\mu=5.35, T_{c^{\prime}}$ can now be calculated as $T_{c^{\prime}}=(\sqrt{2 \mu-1} \mu) \times T_{c}=$ $(\sqrt{2 \times 5.35-1} / 5.35) \times 0.67=0.39 \mathrm{~s}$. Therefore our initial assumption of $T_{c}<T_{n}<T_{c}$ is correct and no iteration is required. Calculated from Equation 15, $u_{m}=$ $(5.35 / 3.43) \times(0.43 / 2 \pi)^{2} \times 1.355 \times 980=9.70 \mathrm{~cm}$. The yield displacement $u_{y}=2965 / 1784=1.66$ $\mathrm{cm}$, and Equation 6 gives the plastic rotation $\theta_{p}=(9.70-1.66) / 400=0.0201$ radians.

The displacement-based design procedure using inelastic design spectra predicted the deformation demand of $9.66 \mathrm{~cm}$ and ductility demand of 5.81 (Table 4), which are essentially identical to the values of $9.70 \mathrm{~cm}$ and 5.35 , respectively, determined by analyzing the designed structure using Equations 11 to 15 . Furthermore, the plastic rotation demand of 0.0201 radians is essentially identical to the acceptable value of 0.02 radians imposed on the design. Just as in Example 1, the procedure has led to a satisfactory design. 
Note that for the examples considered, the displacement-based design procedure using inelastic design spectra leads to a structure with more longitudinal reinforcement and thus higher strength compared to the design based on elastic design spectra for equivalent linear systems. A stronger column is necessary to satisfy the selected design criteria.

\section{CONCLUSIONS}

Direct displacement-based design requires a simplified procedure to estimate the seismic deformation of an inelastic SDF system, representing the first (elastic) mode of vibration of the structure, an MDF system. A simplified procedure that uses the well-known inelastic design spectra has been presented in this paper. With the aid of examples, it has been demonstrated that the procedure (1) provides displacement estimates consistent with those predicted by the well-established concepts of inelastic design spectra, and (2) produces a structural design that satisfies the design criteria for acceptable plastic rotation.

The displacement-based design procedure proposed by several researchers in recent years uses elastic design spectra for equivalent linear systems based on the secant stiffness method or its variations like the substitute structure method. In this paper, we have demonstrated that the deformation and ductility factor that are estimated in designing the structure by this procedure are much smaller than the deformation and ductility demands determined by nonlinear analysis of the system using inelastic design spectra. Furthermore, it has been shown that the plastic rotation demand on structures designed by this procedure may exceed the acceptable value of the plastic rotation. Thus, the design procedure leaves an erroneous impression that the allowable plastic rotation constraint has been satisfied.

While equivalent linear systems may have been appealing in the 1960s and 1970s, their limitations have been recognized for a long time. Jennings (1968) discussed the wide differences among six different equivalent linear systems, and for general use recommended a system that gives much smaller damping than in the secant stiffness method. Iwan and Gates (1979) demonstrated by matching the response of the equivalent linear system to inelastic response spectra that the system damping never exceeded $14 \%$, much less than the secant stiffness method. Chopra and Goel (2000) concluded that the commonly used equivalent linear systems are unacceptably inaccurate in estimating the seismic deformation of inelastic structures. Therefore, they are inappropriate for performance-based design that aims to produce reliable structural designs that satisfy the selected performance criteria.

\section{ACKNOWLEDGMENTS}

This research investigation is supported by the National Science Foundation under Grant CMS-9812531. The authors are grateful for this support.

\section{REFERENCES CITED}

American Concrete Institute (ACI), 1995, Building Code Requirements for Structural Concrete (ACI 318-95) and commentary (ACI 318R-95), Farmington Hills, MI.

Chopra, A. K., 1995, Dynamics of Structures: Theory and Applications to Earthquake Engineering, Prentice Hall, Upper Saddle River, NJ.

Chopra, A. K. and Goel, R. K., 1999, Capacity-demand-diagram methods for estimating seismic deformation of inelastic structures: SDF systems, Report No. PEER-1999/02, Pacific Earthquake Engineering Research Center, University of California, Berkeley, April.

Chopra, A. K. and Goel, R. K., 2000, Evaluation of a NSP to estimate seismic deformation: SDF systems, Journal of Structural Engineering, ASCE, 126 (4), 482-490. 
Iwan, W. D. and Gates, N. C., 1979, The effective period and damping of a class of hysteretic structures, Earthquake Engineering and Structural Dynamics, 7(3), 199-212.

Jennings, P. C., 1968, Equivalent viscous damping for yielding structures, Journal of the Engineering Mechanics Division, ASCE, 94 (EM1), 103-116.

Kowalsky, M., Priestley, M.J.N., and MacRae, G. A., 1994, Displacement-based design of RC bridge columns, Proceedings, $2^{\text {nd }}$ International Workshop on the Seismic Design of Bridges, Queenstown, New Zealand, 1, 138-163.

Krawinkler, H., and Nassar, A. A., 1992, Seismic design based on ductility and cumulative damage demands and capacities, Nonlinear Seismic Analysis and Design of Reinforced Concrete Buildings, P. Fajfar and H. Krawinkler, Eds., Elsevier Applied Science, New York.

MacGregor, J. G., 1997, Reinforced Concrete: Mechanics and Design, Third Edition, Prentice Hall, Upper Saddle River NJ, 485-486.

Miranda, E. and Bertero, V. V., 1994, Evaluation of strength reduction factors for earthquake-resistant design, Earthquake Spectra, 10(2), 357-379.

Moehle, J. P., 1992, Displacement-based design of R/C structures subjected to earthquakes, Earthquake Spectra, 8(3), 403-427.

Newmark, N. M. and Hall, W. J., 1982, Earthquake Spectra and Design, Earthquake Engineering Research Institute, Berkeley, CA.

Priestley, M.J.N., Seible, F., and Calvi, G. M., 1996, Seismic Design and Retrofit of Bridges, John Wiley \& Sons, New York, NY.

Priestley, M.J.N. and Calvi, G. M., 1997, Concepts and procedures for direct displacement-based design, Seismic Design Methodologies for the Next Generation of Codes, Fajfar and Krawinkler (eds.), Balkema, Rotterdam, 171-181.

Riddell, R., Hidalgo, P., Cruz, E., 1989, Response modification factors for earthquake resistant design of short period buildings, Earthquake Spectra, 5(3), 571-590.

Shibata, A. and Sozen, M. A., 1976, Substitute structure method for seismic design in R/C, Journal of the Structural Division, ASCE, 102(ST1), 1-18.

Tso, W. K. and Naumoski, N., 1991, Period-dependent seismic force reduction factors for short-period structures, Canadian Journal of Civil Engineering, 18(4), 568-574.

Veletsos, A. S. and Newmark, N. M., 1960, Effects of inelastic behavior on the response of simple system to earthquake motions, Proceedings of the $2^{\text {nd }}$ World Conference on Earthquake Engineering, Japan, 2, 895-912.

Vidic, T., Fajfar, P., and Fischinger, M., 1994, Consistent inelastic design spectra: strength and displacement, Earthquake Engineering and Structural Dynamics, 23(5), 507-521. 